\title{
Inhibition of Flagellum Morphogenesis in the True Slime Mould Didymium nigripes
}

\author{
By SYLVIA J. KERR* \\ Department of Zoology, University of Minnesota, Minneapolis, 55455 and \\ Department of Biology, Augsburg College, Minneapolis, 55404, U.S.A.
}

(Received 9 November I971; revised 24 April 1972)

\begin{abstract}
SUMMAR Y
Flagellum morphogenesis in the slime mould, Didymium nigripes, involves a sequence of events during which amoebae are changed into biflagellated cells; in a population of cells this transformation is nearly synchronous. In the present study a series of inhibitors thought to inhibit RNA and protein synthesis and microtubule assembly were added in an attempt to characterize the macromolecular events associated with this amoebo-flagellate transformation.

High concentrations of acriflavin and proflavin $(50 \mu \mathrm{g} / \mathrm{ml})$ and lower concentrations of cycloheximide ( 5 to $10 \mu \mathrm{g} / \mathrm{ml}$ ) blocked the morphogenetic process completely. Other reported inhibitors of RNA synthesis and microtubular assembly delayed the onset of flagellum formation for varying periods of time dependent upon the concentrations employed.
\end{abstract}

\section{INTRODUCTION}

Myxamoebae of the true slime mould, Didymium nigripes, which are just entering the stationary phase of growth, readily differentiate into biflagellated cells if they are washed free of bacteria and suspended in $0.05 \mathrm{M}$-phosphate buffer, $\mathrm{pH} \mathrm{6.5.} \mathrm{This} \mathrm{morphogenetic}$ process is quite synchronous and includes several stages (Kerr, I960). Development and elongation of the flagella is described by Kerr (1972). Previous studies (Kerr, I965) have established that morphogenesis is blocked by addition of streptomycin (100 $\mu \mathrm{g} / \mathrm{ml}), 2,4$ dinitrophenol ( $10^{-4} \mathrm{M}$ ), cycloheximide ( $10 \mu \mathrm{g} / \mathrm{ml}$ ) and acriflavin $(50 \mu \mathrm{g} / \mathrm{ml})$.

The current investigation focuses on the question of whether macromolecular events, such as RNA and protein synthesis, are prerequisites for flagellum morphogenesis and on an attempt to sort out the approximate period of time during the incubation period when inhibition of these processes results in blockage of cellular differentiation.

\section{METHODS}

Preparation of amoebae. C-6 amoebae were grown from spores on glucose-peptoneyeast extract agar with brucine (Kerr, 1960) in the presence of Aerobacter aerogenes for 4 days at $2 \mathrm{I}{ }^{\circ} \mathrm{C}$. When the plates were beginning to clear of bacteria the amoebae were harvested in deionized water and washed free of bacteria by sedimenting them five times in a centrifuge at $2000 \mathrm{~g}$.

Incubation conditions. Suspensions of amoebae ( 5 to $10 \mathrm{ml}$ in a $50 \mathrm{ml}$ beaker) were incubated at $2 \mathrm{I}{ }^{\circ} \mathrm{C}$ at a concentration of $\mathrm{I} \times 10^{6}$ amoebae $/ \mathrm{ml}$ in $0.05 \mathrm{M}$-phosphate buffer (0.83 $\mathrm{g} \mathrm{K}_{2} \mathrm{HPO}_{4}+\mathrm{I} \cdot 36 \mathrm{~g} \mathrm{KH}_{2} \mathrm{PO}_{4} / 1$ deionized water), pH 6.5. Periodically the samples

* Present address: I57I Burton, St Paul, Minnesota, 55108, U.S.A. 
were mixed and a drop of the suspension was withdrawn and observed under the phasecontrast microscope. The number of flagellated cells/50 cells was recorded.

Inhibitors tested. The following compounds were tested for their ability to inhibit flagellum morphogenesis: Actinomycin D (Sigma Chemical Company, St Louis, Missouri, U.S.A.); 8-azaguanine (General Biochemical, Chagrin Falls, Ohio, U.S.A.); 5-fluorouracil (Hoffman-Roche, Nutley, New Jersey, U.S.A.); acriflavin (Mann, New York, New York, U.S.A.); proflavin (Allied Chemical from Fisher Scientific, Chicago, Illinois, U.S.A.); colchicine (Sigma); velban (Grand Island Biological, Grand Island, New York, U.S.A.); isopropyl-n-phenyl carbamate (Sigma); ethidium bromide (Sigma); streptomycin sulphate (Squibb, New York, New York, U.S.A.); and cycloheximide (Sigma). Concentrations used are specified in Table I.

\section{Synchrony of the population}

\section{RESULTS}

The synchrony of the morphogenetic process in populations of amoebae was evaluated in the first roo populations studied. In these populations none of the amoebae were flagellated after the washing procedure, at the onset of incubation. Mean values obtained for flagellation in each 50 amoebae counted at the stated intervals from onset of the incubation period were: $30 \mathrm{~min}-8$ ] flagellated (S.D. $=6.7$ ); $45 \mathrm{~min}-27$ flagellated (S.D. $=10$ ); and $60 \mathrm{~min}-47$ flagellated (S.D. $=2 \cdot 25$ ). Data from populations of amoebae was not included in the analysis if the number of flagellated amoebae observed at any of these times differed by more than I S.D. from the mean, except for the $60 \mathrm{~min}$ value where populations with all 50 amoebae flagellated were retained.

\section{Pre-incubation temperature}

An attempt was made to determine whether chilling of the amoebae during the washing procedure might play a role in the time course of flagellum formation. Routinely amoebae were washed and centrifuged at $4{ }^{\circ} \mathrm{C}$ before incubation at $2 \mathrm{I}{ }^{\circ} \mathrm{C}$; the time of exposure to cold ranged from $\mathrm{I} 2$ to $\mathrm{I} 5 \mathrm{~min}$. Other populations of amoebae were washed and centrifuged at $2 \mathrm{r}{ }^{\circ} \mathrm{C}$ before incubation. No difference in the time-course of flagellation was noted in amoebae treated in these two ways. Extending the time of cold exposure to $2 \mathrm{~h}$ before the $2 \mathrm{I}{ }^{\circ} \mathrm{C}$ incubation similarly did not effect the course of flagellation.

\section{Inhibitor studies - RNA synthesis}

Acriflavin, proflavin, actinomycin D, 8-azaguanine and 5-fluorouracil were used to test for a requirement for RNA synthesis during flagellum formation. The effect of various concentrations of these compounds added at the beginning of incubation to populations of amoebae is summarized in Table I. During the period of observation ( 2 to $5 \mathrm{~h}$ ), complete inhibition of flagellation was obtained only in the presence of acriflavin or proflavin $(50 \mu \mathrm{g} / \mathrm{ml})$. High concentrations of actinomycin $\mathrm{D}, 8$-azaguanine and 5 -fluorouracil were effective in delaying the appearance of flagella (see Table I). The effect of these latter compounds was evaluated in terms of delay of flagellum formation in the population of amoebae, i.e. if all of the amoebae in a particular inhibitor became flagellated after $90 \mathrm{~min}$ of incubation, this represented a $30 \mathrm{~min}$ delay in comparison to the untreated population which all became flagellated after $60 \mathrm{~min}$. Non-inhibitory concentrations of EDTA were added at the same time as these compounds in an attempt to increase their uptake, but no enhancement of the inhibitory effect of these compounds was noted. 


\section{Table I. Effect of various compounds on flagellum morphogenesis}

Inhibitor

Concentration

$5 \%$ Ethanol in phosphate buffer $0.1 \%$ DMSO in phosphate buffer

Auxiliary compounds

EDTA in phosphate buffer

$$
\begin{aligned}
& 10^{-4} \text { to } 10^{-7} \mathrm{M} \\
& 5 \times 10^{-4} \mathrm{M} \\
& \mathrm{IO}^{-3} \mathrm{M}
\end{aligned}
$$

Compounds thought to affect RNA synthesis

$$
\begin{aligned}
& \text { Actinomycin D (dissolved in } \\
& \text { ethanol) in phosphate buffer } \\
& \text { Actinomycin D (as above) } \\
& \text { in } 0.1 \% \text { DMSO } \\
& \text { Actinomycin D (as above) } \\
& \text { in } 10^{-7} \text { to } 10^{-5} \mathrm{M} \text {-EDTA }
\end{aligned}
$$

8-Azaguanine in phosphate buffer or in buffer with $10^{-6}$ to $\mathrm{IO}^{-4} \mathrm{M}$-EDTA

5-Fluorouracil in phosphate buffer

5-Fluorouracil (as above)

in $10^{-4} \mathrm{M}$-EDTA

5 -Fluorouracil (as above) in $10^{-7}$ to $10^{-5}$ EDTA

Acriflavin in phosphate buffer

Proflavin in phosphate buffer

Compounds thought to affect protein synthesis

$$
\text { Cycloheximide }
$$

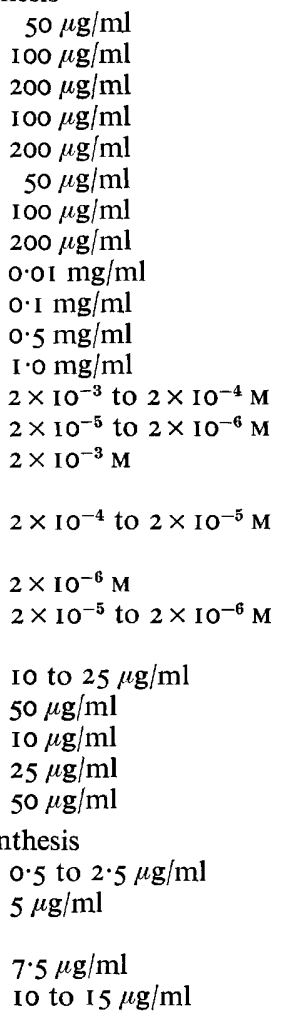

Compounds thought to affect microtubular assembly

Colchicine in phosphate buffer or in buffer with $10^{-5}$ to $10^{-4} \mathrm{M}$-EDTA

\section{Velban (vinblastine sulphate) in phosphate buffer}
Iso-propyl- $n$-phenyl carbamate (dissolved in ethanol) in phosphate buffer

0.01 to $1.0 \mathrm{mg} / \mathrm{ml}$ $2 \mathrm{mg} / \mathrm{ml}$ $5 \mathrm{mg} / \mathrm{ml}$

$10 \mathrm{mg} / \mathrm{ml}$ 0.001 to $0.005 \mu \mathrm{g} / \mathrm{ml}$ $0.0 \mathrm{I}$ to $0 . \mathrm{I} \mu \mathrm{g} / \mathrm{ml}$ $0.5 \mu \mathrm{g} / \mathrm{ml}$

$2.5 \mu \mathrm{g} / \mathrm{ml}$ $25 \mu \mathrm{g} / \mathrm{ml}$

Other compounds

Ethidium bromide in phosphate buffer

I to $10 \mu \mathrm{g} / \mathrm{ml}$ 25 to $50 \mu \mathrm{g} / \mathrm{ml}$ $\mathrm{I} 00 \mu \mathrm{g} / \mathrm{ml}$

Streptomycin sulphate in phosphate buffer
Time when $90 \%$ of amoebae were flagellated (normally at $60 \mathrm{~min}$ )

No delay

20 to 30 min delay

Amoebae encysted; no flagellation

No delay

30 min delay

No delay

I 5 min delay

30 min delay

45 min delay

45 to 60 min delay

No delay

20 to 30 min delay

30 min delay

No delay

15 min delay

30 to 40 min delay

Amoebae lysed

15 min delay

20 to 30 min delay

No delay for population but first

flagella appeared later

I 5 min delay; first flagella appeared later

No delay; first flagella appeared later o to 15 min delay; first flagella appeared later

No delay

Inhibition

I 5 to 20 min delay

40 to $45 \mathrm{~min}$ delay

Inhibition

No inhibition

Inhibition in 80 to $100 \%$ of

population

Inhibition in $100 \%$ of population Inhibition and toxic effects

(encystation)

No delay

30 min delay

$45 \mathrm{~min}$ delay; $30 \mathrm{~min}$ delay before first flagella appeared

40 to $75 \mathrm{~min}$ delay

No delay

I 5 min delay

45 min delay; 30 min delay before first flagella appear

No delay

30 min delay

No delay

15 min delay

$45 \mathrm{~min}$ delay

$45 \mathrm{~min}$ delay

75 min delay 


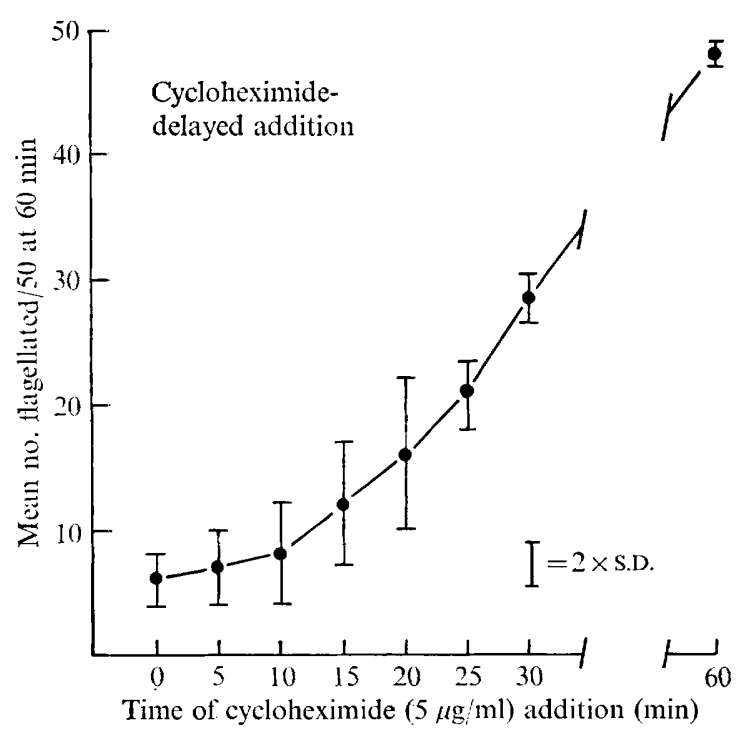

Fig. I. Effect of addition of cycloheximide to amoebae undergoing morphogenesis. Cycloheximide addition delayed for varying periods of time (horizontal axis) resulted in differing numbers of cells undergoing flagellation (vertical axis).

Definition of the period of time when the amoebae were sensitive to inhibition of RNA synthesis was attempted by postponing the addition of effective concentrations of acriflavin, proflavin and 8-azaguanine until 10, 15, 20, 25 or 30 min after the commencement of normal incubation. Acriflavin and proflavin were completely inhibitory when added during the first $30 \mathrm{~min}$. When addition of 8-azaguanine was postponed for 10,20 or $30 \mathrm{~min}$, the delay before the amoebae became flagellated was decreased as addition was delayed.

\section{Protein synthesis}

Cycloheximide, a reported inhibitor of protein synthesis, completely and reversibly inhibited flagellation without obvious damage to the amoebae. Inhibition of flagellation continued as long as the amoeba remained in a solution of cycloheximide. The period of maximum sensitivity to cycloheximide was determined by splitting a population of amoebae into eight portions, postponing addition of cycloheximide $(5 \mu \mathrm{g} / \mathrm{ml})$ until after $5,10,15$, $20,25,30$ or $60 \mathrm{~min}$ of incubation, and determining the number of amoebae per 50 cells which were flagellated at $60 \mathrm{~min}$. Cycloheximide added during the first $10 \mathrm{~min}$ of incubation exhibited a maximum inhibitory effect and sensitivity to the compound decreased as incubation time before addition was increased (Fig. 1 ).

When amoebae inhibited from forming flagella by cycloheximide were sedimented by spinning at $5000 \mathrm{~g}$ and then resuspended in phosphate buffer at $2 \mathrm{I}{ }^{\circ} \mathrm{C}$ without cycloheximide, they all grew flagella. Recovery from cycloheximide inhibition was studied in a series of experiments where cycloheximide $(7.5 \mu \mathrm{g} / \mathrm{ml})$ was added to a population of amoebae at the beginning of the incubation period, washed out of separate portions of these populations at intervals, and the number of flagellated amoebae per 50 amoebae was counted at 15 min intervals. Amoebae exposed to cycloheximide in this manner and resuspended in phosphate buffer always showed delayed flagellation in comparison to that 


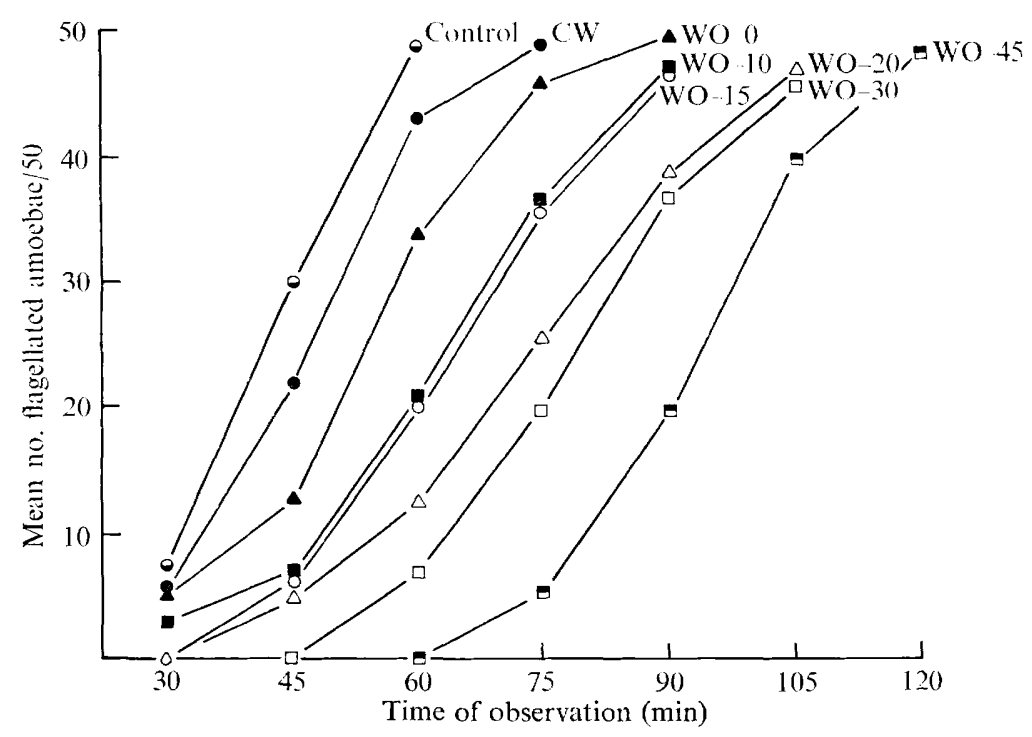

Fig. 2. Delay in appearance of flagellated amoebae after treatment with $7 \cdot 5 \mu \mathrm{g}$ cycloheximide $/ \mathrm{ml}$ for varying periods of time. Control - amoebae incubated under standard conditions; $C W$, control amoebae subjected to cold washing procedure; WO-0, WO-10, WO-I 5, WO-20, WO-30, WO-45 cells placed in $7.5 \mu \mathrm{g}$ cycloheximide $/ \mathrm{ml}$ at the beginning of incubation and then subsequently removed from cycloheximide, e.g. WO-IO: cells placed in cycloheximide at time 0 and removed from cycloheximide after Io min.

of amoebae not exposed to cycloheximide (Fig. 2). The behaviour of amoebae after exposure to cycloheximide can be summarized as follows: (i) the delay in appearance of flagella caused by the cold wash is almost identical to a $5 \mathrm{~min}$ difference in incubation time in cycloheximide later in the experiment (e.g. comparing 15 and $20 \mathrm{~min}$ of incubation before washout). Thus the amount of delay caused by the cold treatment seems to be directly proportional to the amount of time spent in the cold; (ii) amoebae exposed to cycloheximide briefly (o time washout - in reality cycloheximide exposure up to I min could have occurred before pelleting) were delayed proportionately longer than their exposure to cycloheximide. The observed delay was proportional to about ro min of exposure to cycloheximide later in the time course of morphogenesis; (iii) amoebae exposed to cycloheximide for longer intervals showed additional delay in flagellation after washout directly proportional to the length of exposure to cycloheximide.

\section{Microtubular assembly}

Colchicine and velban (vinblastine sulphate), inhibitors of microtubular assembly in other organisms, were tested for their ability to block flagellum production. At high concentrations flagellum production was delayed but not blocked (Table I). Addition of non-inhibitory concentrations of EDTA in the presence of colchicine did not alter the effectiveness of colchicine.

Isopropyl-n-phenyl carbamate (IPC), a mitotic inhibitor thought to dissociate microtubules, was tested in a series of delayed addition and wash out experiments. IPC $(25 \mu \mathrm{g} / \mathrm{ml})$ added during the first $20 \mathrm{~min}$ of incubation delayed flagellation in the population for $30 \mathrm{~min}$. If this concentration was added during the next 15 to $20 \mathrm{~min}$ before flagellates appeared in the untreated population, morphogenesis of half the cells in the population 
was delayed for $30 \mathrm{~min}$. If added after the population was flagellated, the flagella remained intact.

When IPC was added at the beginning of incubation and removed by washing the amoebae at $5000 \mathrm{~g}$ and then resuspending them in phosphate buffer, the inhibitory effect was reversed, but no delay in flagellum morphogenesis occurred when IPC was removed immediately. When IPC remained in the incubation medium for $15 \mathrm{~min}$ or longer before removal, the percentage of amoebae showing inhibition after $60 \mathrm{~min}$ of incubation progressively increased. Populations of cells exposed to IPC for varying periods of time were uniformly flagellated after $90 \mathrm{~min}$ of incubation.

\section{Other inhibitors}

Ethidium bromide, an inhibitor of mitochondrial nucleic acid synthesis in other systems, when tested at concentrations of 25 and $50 \mu \mathrm{g} / \mathrm{ml}$, produced a slight delay in morphogenesis, and at $100 \mu \mathrm{g} / \mathrm{ml}$ flagellation was delayed for about $45 \mathrm{~min}$. When addition of $100 \mu \mathrm{g} / \mathrm{ml}$ was postponed, delay in flagellation was decreased, e.g. at $10 \mathrm{~min}$ the delay lasted $30 \mathrm{~min}$ and at $20 \mathrm{~min}$ the delay lasted only $15 \mathrm{~min}$. At $30 \mathrm{~min}$ there was no effect on flagellation.

Amoebae incubated in the presence of streptomycin $(250$ to $500 \mu \mathrm{g} / \mathrm{ml})$ did not become flagellated during the first hour of incubation but did eventually become flagellated. As streptomycin concentration was increased, the delay before the appearance of flagella was also increased (Table I).

In one series of experiments streptomycin $(250 \mu \mathrm{g} / \mathrm{ml})$ was added once at the beginning of incubation and again at various intervals in the morphogenetic process. The number of flagellated amoebae per 50 amoebae was scored at intervals and compared with amoebae which received single doses of streptomycin (either $250 \mu \mathrm{g} / \mathrm{ml}$ or $500 \mu \mathrm{g} / \mathrm{ml}$ ) at the beginning of incubation. If $250 \mu \mathrm{g} / \mathrm{ml}$ were added at time 0 and again after $\mathrm{I} 5,45$ or $60 \mathrm{~min}$, the amoebae behaved like amoebae which had received a single dose of $250 \mu \mathrm{g} / \mathrm{ml}$ at the beginning of incubation. If the second dose of $250 \mu \mathrm{g} / \mathrm{ml}$ was added $30 \mathrm{~min}$ after the beginning of incubation, the degree of flagellation was the same as if $500 \mu \mathrm{g} / \mathrm{ml}$ had been added at the beginning of incubation. This special sensitivity of cells to additional streptomycin at $30 \mathrm{~min}$ of incubation suggests that recovery from streptomycin inhibition may be correlated with destruction or neutralization of the compound by the amoebae.

\section{DISCUSSION}

Synchronous differentiation of cells in a eukaryotic system which can be easily manipulated provides a relatively rare and valuable opportunity to study macromolecular events in cellular differentiation. Flagellum synthesis and assembly have been studied previously in several normally flagellated organisms: Ochromonas danica, Astasia longa, Euglena gracilis (Rosenbaum \& Child, I967); Peranema trichophorum (Tamm, 1967); and Chlamydomonas reinhardi (Rosenbaum, Moulder \& Ringo, 1969). In several of these systems flagellum synthesis was blocked in the presence of cycloheximide and colchicine; Rosenbaum et al. have conclusively shown that flagellum synthesis in Chlamydomonas can be separated into stages of protein synthesis (blocked by cycloheximide) and microtubular assembly (blocked by colchicine).

The amoebo-flagellate transformation which occurs in the true slime moulds and in some soil amoebae, e.g. Naegleria gruberi (see Fulton \& Dingle, 1967) involves not only organellar growth but also differentiation of amoebae into a new morphological type. 
Flagellum morphogenesis in $N$. gruberi is blocked early during incubation by the presence of actinomycin D (Wade \& Satir, 1968), suggesting that induction of morphogenesis in this system requires RNA synthesis. Failure of routinely employed concentrations of actinomycin D to block flagellum morphogenesis in Didymium nigripes cannot be construed as evidence that DNA-dependent RNA synthesis is not involved in the morphogenetic process because acriflavin and proflavin do block morphogenesis. Considering that the natural habitat of these organisms is in soil where antibiotic-producing organisms are often found, it is not unreasonable to postulate that they have evolved some means of destroying the effectiveness of this compound or of excluding it from the cells. This view is supported by the observation that $D$. nigripes can grow and divide in the presence of actinomycin D (Kerr, I965) and that the plasmodial stage of Physarum polycephalum, a closely related slime mould, has also been shown to be relatively insensitive to actinomycin D (see Rusch, 1970). Proflavin, one of the inhibitors effective in blocking flagellation in D. nigripes, has been shown to inhibit $\left[\mathrm{H}^{3}\right]$ uridine uptake into RNA fractions of plasmodia of Physarum polycephalum specifically at concentrations of $25 \mu \mathrm{g} / \mathrm{ml}$ (Sauer, Babcock \& Rusch, 1969).

Cycloheximide inhibition of flagellum morphogenesis strongly suggests that protein synthesis is involved in the amoebo-flagellate transformation. Typically the greatest effect of low concentrations of cycloheximide is to block the incorporation of amino acids into protein (Siegel \& Sisler, I963; Ennis \& Lubin, I964; Cummins, Brewer \& Rusch, I965; Rosenbaum et al. 1969). Attempts to link cycloheximide to inhibition of respiratory metabolism in Euglena gracilis have been unsuccessful (Kirk, 1970). Cycloheximide added to differentiating amoebae of Didymium nigripes immediately halted flagellar elongation; thus is seems probable that its effect in this system is to block synthesis of protein required either for flagellum synthesis or assembly.

Another process in flagellum production which has been studied in other systems is the assembly of precursors into microtubular arrays. Microtubule assembly in Chlamydomonas reinhardi is reported to be blocked by high concentrations of colchicine (Rosenbaum et al. 1969). This is thought to be due to the binding of colchicine to microtubular proteins (Borisy \& Taylor, I967). However in Naegleria gruberi concentrations of colchicine up to $5 \times \mathrm{IO}^{-2} \mathrm{M}$ failed to block or delay flagellum formation (Yuyama, $197 \mathrm{I}$ ), but mercaptoethanol did block flagellum morphogenesis (Wade \& Satir, I968). In ciliary regenerating systems of Stentor coeruleus concentrations from 4 to $2 \times \mathrm{IO}^{-4} \mathrm{M}$-isopropyl- $n$-phenyl carbamate were capable of reversibly blocking membranellar band regeneration (Banerjee \& Margulis, I969). Delay of morphogenesis, not total inhibition of microtubule assembly, was found when similar compounds were tested on Didymium nigripes.

Mitochondrial function may play an important role in flagellum morphogenesis. Schuster (1965) described changes in the mitochondrial structure of Didymium nigripes associated with the amoebo-flagellate transformation. Kerr (1965) reported inhibition of flagellation in the same organism if mitochondrial oxidative phosphorylation was blocked by the presence of $1 \mathrm{IO}^{-4} \mathrm{M}-2,4$ dinitrophenol or by incubating the cells in a $\mathrm{N}_{2}$ atmosphere. Delay of flagellation induced by ethidium bromide during the early stages of incubation may also suggest mitochondrial involvement, since $10 \mu \mathrm{g} / \mathrm{ml}$ specifically blocks DNA replication in plasmodial mitochondria of the slime mould, Physarum polycephalum (Horwitz \& Holt, I97I). Perhaps mitochondrial replication or transformation is one of the early steps required for flagellum differentiation.

Thus it seems that several processes involved in flagellum morphogenesis can be identified through the use of compounds whose mode of inhibition has been defined in other systems. 
Confirmation of the mode of action in Didymium nigripes is impractical until this organism can be grown satisfactorily in axenic culture. When comparing time of release of inhibition (determined by delayed-addition experiments) a tentative time sequence for events involved in flagellum morphogenesis can be constructed. Steps inhibited by streptomycin and ethidium bromide are important during the first 10 min of incubation and become less important thereafter. Involvement of ethidium bromide in mitochondrial-DNA synthesis and of streptomycin in $70 \mathrm{~S}$ ribosomal-protein synthesis suggest that mitochondrial change may be important at this stage. The importance of cellular-RNA synthesis, as demonstrated by proflavin inhibition, is prominent during the first $20 \mathrm{~min}$ of incubation and declines in importance thereafter. Sensitivity of the morphogenetic process to cycloheximide, presumably an inhibitor of protein synthesis, begins to decline after the first $15 \mathrm{~min}$ of incubation. However, cycloheximide added after flagella have appeared will immediately halt elongation (Kerr, 1972). Total sensitivity to isopropyl-n-phenyl carbamate does not begin to decrease until after 20 min of incubation has elapsed; during this period of time flagellar protein has been synthesized to allow production of visible flagella in some cells (Fig. I). Thus presumably the IPC-sensitive step follows that stage of protein synthesis.

I wish to thank Dr Norman Kerr, Department of Zoology, University of Minnesota, and Drs Ralph Sulerud and Neal Thorpe, Department of Biology, Augsburg College, for use of their laboratories and Mrs Lyn Steere for assistance in the preparation of the Figures.

\section{REFERENCES}

BANerJee, S. \& MARgulis, L. (I969). Reversible inhibition of cilia regeneration in Stentor coeruleus by isopropyl- $n$-phenyl carbamate. Nature, London 224, I80-18I.

BORISY, G. G. \& TAYLOR, E. W. (1967). The mechanism of action of colchicine. Colchicine binding to sea urchin eggs and the mitotic apparatus. Journal of Cell Biology 34, 535-547.

Cummins, J. E., Brewer, E. N. \& Rusch, H. P. (1965). The effect of actidione on mitosis in the slime mold Physarum polycephalum. Journal of Cell Biology 27, 337-34I.

ENNIS, H. L. \& LuBIN, M. (1964). Cycloheximide: Aspects of inhibition of protein synthesis in mammalian cells. Science, New York 146, I474-1476.

Fulton, C. \& Dingle, A. D. (1967). Appearance of the flagellate phenotype in populations of Naegleria amoebae. Developmental Biology 15, I65-19I.

Horwitz, H. B. \& Holt, C. E. (197I). Specific inhibition by ethidium bromide of mitochondrial DNA synthesis in Physarum polycephalum. Journal of Cell Biology 49, 546-553.

KERR, N. S. (1960). Flagella formation by myxamoebae of the true slime mold, Didymium nigripes. Journal of Protozoology 7, $103-108$.

KERR, N. S. (1965). Inhibition by streptomycin of flagella formation in a true slime mold. Journal of Protozoology 12, 276-278.

KERR, S. J. (1972). Flagellum growth and regeneration in the true slime mould Didymium nigripes. Journal of General Microbiology 72, 429-437.

KIRK, J. T. O. (1970). Failure to detect effects of cycloheximide on energy metabolism in Euglena gracilis. Nature, London 226, 182.

Rosenbaum, J. L. \& CHILd, F. M. (I967). Flagellar regeneration in protozoan flagellates. Journal of Cell Biology 34, 345-364.

Rosenbaum, J. L., Moulder, J. E. \& Ringo, D. (1969). Flagellar elongation and shortening in Chlamydomonas. Journal of Cell Biology 4r, 600-6r9.

Rusch, H. P. (1970). Some biochemical events in the life cycle of Physarum polycephalum. In Advances in Cell Biology, vol. I, pp. 297-328. Edited by D. M. Prescott, L. Goldstein \& E. McConkey, New York: Appleton-Century-Crofts.

SAutr, H. W., Babcock, K. L. \& Rusch, H. P. (1969). Sporulation in Physarum polycephalum: A model system for studies on differentiation. Experimental Cell Research 57, 319-327. 
SCHuSTER, F. L. (1965). Ultrastructure and morphogenesis of solitary stages of true slime molds. Protistologica 2, 49-62.

SiEgel, M. R. \& SiSLER, H. D. (1963). Inhibition of protein synthesis in vitro by cycloheximide. Nature, London 200, 675-676.

TAMM, S. L. (1967). Flagellar development in the protozoon Peranema trichophorum. Journal of Experimental Zoology 164, 163-1 86.

WADE, J. \& SATIR, P. (1968). The effect of mercaptoethanol on flagellar morphogenesis in the amoeboflagellate Naegleria gruberi (Schardinger). Experimental Cell Research 56, 8I-92.

YUYAMA, S. (I97I). The effects of selected chemical agents on the amebaflagellate transformation in Naegleria gruberi. Journal of Protozoology 18, 337-343. 